\title{
Acute Testicular Torsion: The Need of Health Awareness Moroccan Experience
}

El Anzaoui J*

Department of Urology, Military Hospital Avicenna, Marrakech, Morocco

*Corresponding author: J. El Anzaoui, Department of Urology, Military hospital Avicenna, Urology, Marrakech, Morocco, Tel: +00212 661331835; E-mail:

jihad.elanzaoui@gmail.com

Rec date: Feb 19, 2015, Acc date: Jun 09, 2015, Pub date: Jun 16, 2015

Copyright: (C) 2015 El Anzaoui J. This is an open-access article distributed under the terms of the Creative Commons Attribution License, which permits unrestricted use, distribution, and reproduction in any medium, provided the original author and source are credited.

\section{Introduction}

The acute testicular torsion (ATT) is a vascular emergency. It occurs when the torsion of spermatic cord twists the blood vessels and stops the flowing of testicular blood.

The rapid evolution of testicular torsion in the absence of treatment leads to ischemic necrosis (Figure 1), and testicular loss. The main symptom is an unilateral acute scrotal pain, that can also be caused by infected or tramatic testis. And time remains the greatest challenge.

The six-hour intervening time makes this emergency difficult to manage [1], and the urgent surgical exploration for confirmation of diagnosis and salvation of testis is the only solution [2]. Unfortunately, this health problem still been ignored by the public [3].

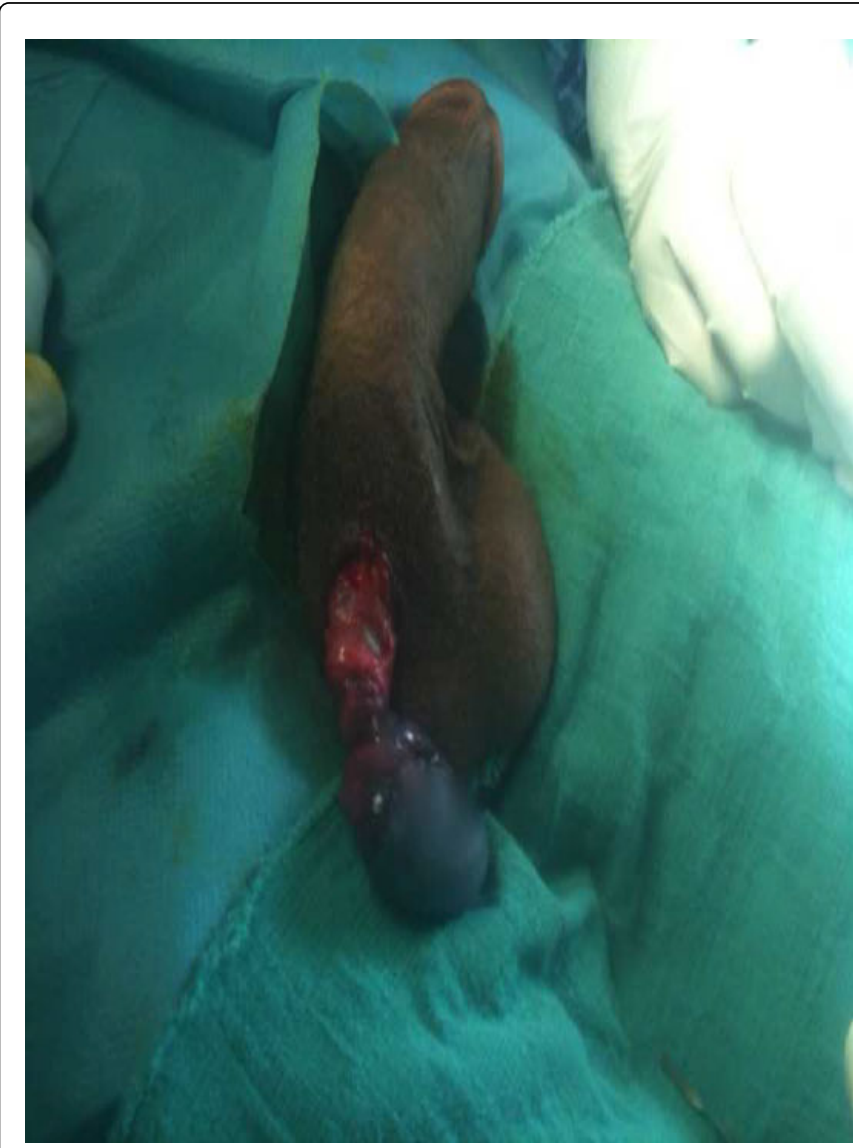

Figure 1: Surgical exploration: testicular torsion with testicular necrosis

\section{Gravity of Testicular Loss}

The impact of testicular death and orchidectomy is physical and psychological. Most often, testicular torsion occurs in adolescence [4]. For adolescents, whose personality is being formed, the orchidectomy represents an extreme psychological and physical aggression. Besides its potential impact on fertility [1], Testicular torsion rises in severity if occurs on a single testis demanding an androgenic substitution per life, with a definit infertility. This impact on fertility can occur even on salvaged testis. But it seems to be less severe in this case [3]. On the psychological level, orchidectomy has the particularity to touch the « center » of virility in men. In fact, the testicles possessing a functional value becomes "vital" organ in the period of adolescence and puberty. Thus, the impact on the sexual identity of adolescents seems inevitable, but its depth remains to be assessed. Indeed, Unfortunately, we do not find in the literature, as we know, any study dealing with the consequences of orchiectomy on the personality of the young men in particular.

\section{Need of Health Awareness}

The ATT is a dramatic accident. The key of solution is the prevention of the delay of treatment by general public health awareness. In a world where communication has become prevalent, the health awareness has become very common in all health systems over the world. Thus, awareness conducted by media is currently the most effective way of prevention.

The clinical and evolutive features of ATT make it very close to any other vascular emergency. In spite of its vascular emergency characteristics and dramatic consequences, the ATT does not have the same impact of acute myocardal infarction or ischemic cerebral stroke in the public conscience. We propose to call it " acute testicular infarction by spermatic cord torsion» or «Acute ischemic testicular stroke by spermatic cord torsion " to be more persuasive to the public awareness.

\section{Morocco: Current Situation}

Morocco is a developing country that has made in recent years great progress in developing care structures and in health awareness. In contrast, it is clear that many more efforts are still required. Unfortumately, Morocco suffers from lack of statistic information about many health problems and about ATT in particular. In our experience we have treated 52 ATT between January 2005 and December 2014 . We have noted that $72 \%$ of testicular torsion are received lately at the emergency room (after six hours from the beginning of pain). That have lead to $53 \%$ of orchidectomy. $85 \%$ of our patient ignored completely how much is urgent to manage an acute scrotal pain, and have attempted automedication at home. And more than $92 \%$ have never heard about ATT.The general prevention of this 
Citation: El Anzaoui J (2015) Acute Testicular Torsion: The Need of Health Awareness Moroccan Experience. J Steroids Horm Sci 6: 156. doi:

Page 2 of 2

scourge is possible only by making an effort of rising awareness and promoting education.

\section{Conclusion}

The ATT is easy to diagnosis and to treat but at the same time have serious complications in case of late intervention. The role of media is taken for granted for the prevention of delayed diagnosis and treatment of ATT. The message is simple: rush to emergencies for any acute scrotal pain. A media coverage among large parts of the society is of paramount necessity. Physicians and public authorities are called out.

\section{References}

1. Cost NG, Bush NC, Barber TD, Huang R, Baker LA (2011) Pediatric testicular torsion: demographics of national orchiopexy versus orchiectomy rates. J Urol 185(6): 2459e63.

2. Amato R, Legrand G, Pocard M (2014) Traitement d'une torsion testiculaire. Journal de Chirurgie Viscérale.

3. DaJusta DG, Granberg CF, Villanueva C, Linda A (2013) Baker. Contemporary review of testicular torsion : New concepts, emerging technologies and potential therapeutics. Journal of Pediatric Urology 9, 723: e730

4. Selbst SM, Friedman MJ, Singh SB. (2005) Epidemiology and etiology of malpractice lawsuits involving children in US emergency departments and urgent care centers. Pediatr Emerg Care 21: 165e9. 